\title{
TRADUÇÃO COMENTADA DE “ICH STERBE”, DE NATHALIE SARRAUTE
}

\section{A COMMENTED TRANSLATION OF “ICH STERBE”, BY NATHALIE SARRAUTE}

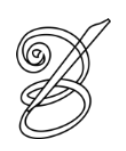

Nicolás GÓMEZ ${ }^{1}$

Universidade de Brasília

Resumo: Este artigo consiste numa tradução comentada. É apresentada uma tradução, para o espanhol, do texto "Ich sterbe", da escritora russo-francesa Nathalie Sarraute. O comentário consiste na explicitação de uma série de critérios que nortearam o trabalho de tradução, e na apresentação de exemplos ilustrativos dos critérios, tomados da tradução. A definição dos critérios se baseia, por sua vez, na análise do texto original, considerado no contexto da obra da autora. Na análise do texto e na exposição do projeto, são desenvolvidas e utilizadas as noções teóricas de heterogeneidades enunciativas, de Jacqueline Authier-Revuz (1984), e de ritmo, segundo Henri Meschonnic (2012).

Palavras-chave: Tradução comentada. Nathalie Sarraute. Francês. Espanhol. Heterogeneidade enunciativa.

Abstract: This paper consists in a commented translation. On the one hand, we propose a translation of the text "Ich sterbe", by Russian-French writer Nathalie Sarraute, into Spanish. The commentary, on the other hand, seeks to expose a series of criteria which acted as guidelines for the production of the translated text, and bring some examples about those criteria, taken from the original and translated text. The definition of those guidelines, in turn, is based upon an analysis of the original French text, considered in the wider context of the works and literary project of the author. Notions like enunciative heterogeneity, by Jacqueline Authier-Revuz, or rhythm, according to Henri Meschonnic, are brought as conceptual tools for the analysis of the original text and the definition of the translation project.

Keywords: Commented translation. Nathalie Sarraute. French. Spanish. Enunciative heterogeneity.

RECEBIDO EM: 02/06/2018

ACEITO EM: 25/06/2018

PUBLICADO EM: julho 2018 

ste artigo é um desdobramento do trabalho realizado no segundo semestre de 2017 no contexto da disciplina Oficina de Tradução, oferecida pelo Postrad e ministrada pela

professora Germana Henriques Pereira. É apresentada uma proposta de tradução para o espanhol de "Ich sterbe", texto da escritora Nathalie Sarraute.

As seções primeira e segunda deste artigo apresentam a autora, percorrem suscintamente o contexto em que a sua obra faz irrupção e trazem algumas caraterísticas centrais da obra e do projeto literário de Sarraute. Também se exibe uma mini-pesquisa histórica sobre a tradução das obras da autora para a língua espanhola. Uma terceira seção consta da proposta de tradução para o espanhol do texto "Ich sterbe". Ele é apresentado em paralelo com o texto original em um quadro de duas colunas. O leitor notará uma defasagem entre os textos francês e espanhol, que não foi compensada graficamente com linhas em branco (procedimento que facilitaria o cotejo entre os textos original e traduzido). As razões dessa omissão também serão explicadas mais à frente. Na quarta seção, se expõe uma análise do texto original. Visa-se a exibir os enjeux - núcleos de significância, questões chave de tradução, aspectos problemáticos - que aquele coloca à tradução. A quinta e última seção consiste em um comentário da tradução, a partir das considerações realizadas nas secções anteriores.

\section{Autora, contexto e obra}

Natalia Cherniak nasce em 1900 na Rússia e se estabelece na França em 1909. Nathalie Sarraute - seu nome literário - nasce, talvez, em 1939, com a publicação do seu primeiro livro, Tropismes (escrito em 1932).

Uma das posições que embasam e articulam a proposta da autora, no contexto do seu sistema cultural e literário, é uma crítica da "forma literária do romance engajado", porquanto ele seria "uma repetição de clichês de linguagem e de estética" (PEREIRA, 2012). Já o contexto de pós-Guerra traz modificações de alcance amplo, na cultura em geral e no campo literário em particular. Mais especificamente, se produzem mudanças na estrutura do romance, marcadas pelo questionamento da linguagem, em particular a descrença da mesma "como fator de ligação e de entendimento entre os homens, da linguagem como emancipadora, tornando-se, assim, objeto de derrisão" (PEREIRA, 2012). Nesse contexto aparecem, na vida literária francesa mas também europeia -, Nathalie Sarraute, Samuel Beckett, Alain Robbe-Grillet, entre vários outros. Esses escritores passam a ser identificados como grupo e conhecidos sob o rótulo de Nouveau Roman. No entanto, cada um desses escritores vai desenvolver, na sua proposta literária, uma maneira singular de questionamento e reinvenção da linguagem. 


\section{Sobre a obra de Nathalie Sarraute}

No que diz respeito a Sarraute, o seu foco é "descobrir os recônditos da alma humana, o lugar escondido onde se forma a sensação e, em seguida, construir um artefato estético" (PEREIRA, 2012). Assim, uma primeira resposta vem em 1939 com os tropismos. Estes são definidos como "movimentos larvários que se formam às portas da consciência e que se mostram à luz do dia" (PEREIRA, 2012). A partir dali a obra em geral se orienta ao estudo da irrupção e formação da linguagem em estratos que podemos chamar de pre-conscientes. Essa formação não se dá como voz única, mas em modo de sous-conversations, onde múltiplas vozes se encontram nessa consciência em germe. Assim, a obra de Sarraute abunda em diálogos. Estes, porém, não necessariamente acontecem entre personagens clássicos (objetivados, exteriores), mas entre vozes que se confundem, que se localizam nas dobras do discurso do narrador, pondo em questão a sua integridade monolítica.

Neste sentido, a proposta literária de Sarraute realiza na prática um questionamento do artefato literário clássico, do romance francês canônico. Um dos alvos privilegiados desse questionamento é a figura e o estatuto do narrador. Em Sarraute, este já não é um narrador onisciente e como en écart com relação a seu próprio discurso. Já não é um mestre que orquestra um mundo ficcional fechado e lógico. A narração é a voz interior, a voz da consciência que tateia e se procura. A respeito desse tateio no germe da literatura, Antoine Berman aponta: “A obra final é acabada, definitiva, mas sempre conserva algo dessa fase de gestação, de tateio, a partir da qual ela bifurcou para sua figura final”2 (BERMAN, 1995, p. 71, tradução nossa). Neste sentido, podemos pensar que o projeto literário de Sarraute pretende exibir e tematizar essa gestação na obra "final".

Por sua vez, essa consciência que tateia não é singular: é múltipla, é aberta. É emaranhada. Em diálogo com diversas correntes de pensamento que questionam a centralidade do sujeito, mas de um modo original, a obra de Sarraute atualiza constantemente a pergunta de quem fala no discurso. O que interessa não é dar uma resposta unívoca, mas levar a pergunta ao extremo, no decorrer da prática literária.

Nesse tateio, nesses sub-diálogos, há um lugar para o leitor. Mais precisamente, essas conversações - ou sub-conversações - realizam um movimento de abertura em direção ao leitor. Um movimento de interpelação e de inclusão do leitor no curso (ou no discurso) do texto. Assim, o dispositivo literário sarrautiano coloca o leitor como mais uma dessas vozes que se convocam no movimento germinal da palavra. 
O texto "Ich sterbe", cuja tradução para o espanhol apresento neste artigo, faz parte do livro L'usage de la parole, publicado em 1980 pelo selo editor Gallimard (SARRAUTE, 1980). Até onde pudemos apurar, trata-se de uma obra ainda não traduzida para o espanhol. Uma pesquisa nos registros de ISBN da Espanha, da Argentina, do México e da Colômbia (principais centros editores em língua espanhola) não produziu resultados positivos para o título. No entanto, outras obras da autora foram publicadas em língua espanhola. No México e na Colômbia não se registram títulos da autora. Já na Argentina, foi publicado Retrato de un desconocido, na editora Adriana Hidalgo, no ano de 2001 (AGENCIA ARGENTINA DE ISBN). No registro do texto no site argentino de ISBN, não se faz menção ao tradutor. A pesquisa online revela que a obra foi traduzida por Roberto Bixio (LA CENTRAL). Trata-se da tradução da obra Portrait d'un inconnu, publicado por Robert Marin em 1948, e novamente pela Gallimard em 1956. Na Espanha, registram-se 14 (quatorze) publicações da autora (BASE DE DATOS DE LIBROS EDITADOS EN ESPAÑA). Onze (11) delas são em língua castelhana (as três restantes em catalão). São: Las frutas de oro (Seix Barral, 1965); La era del recelo (Guadarrama, 1967); El señor Marteau (Planeta, 1971); Los oye usted? (Barral Editores, 94 1974); Infancia (Alfaguara, 1984); El planetario (Alfaguara, 1985); Entre la vida y la muerte (Alfaguara, 1985); Tropismos (Tusquets, 1987); Tú no te quieres (Tusquets, 1992); Por un sí o por un no (Asociación de Directores de Escena, 1994); La palabra amor y otros relatos (Debolsillo, 2000). 


\section{Tradução}

\begin{tabular}{|c|c|}
\hline ICH STERBE & ICH STERBE \\
\hline $\begin{array}{l}\text { Ich sterbe. Qu'est-ce que c'est? Ce } \\
\text { sont des mots allemands. Ils signifient je } \\
\text { meurs. Mais d'où, mais pourquoi tout à } \\
\text { coup? Vous allez voir, prenez patience. Ils } \\
\text { viennent de loin, ils reviennent (comme on dit } \\
\text { : «cela me revient ») du début de ce siècle, } \\
\text { d'une ville d'eau allemande. Mais en réalité } \\
\text { ils viennent d'encore beaucoup plus loin... } \\
\text { Mais ne nous hâtons pas, allons au plus près } \\
\text { d'abord. Donc au début de ce siècle - en } \\
\text { l904, pour être plus exact - dans une } \\
\text { chambre d'hôtel d'une ville d'eaux allemande } \\
\text { s'est dressé sur son lit un homme mourant. Il } \\
\text { était russe. Vous connaissez son nom : } \\
\text { Tchekhov, Anton Tchekhov. C'était un } \\
\text { écrivain de grande réputation, mais cela } \\
\text { importe peu en l'occurrence, vous pouvez } \\
\text { être certains qu'il n'a pas songé à nous } \\
\text { laisser un mot célèbre de mourant. Non, pas } \\
\text { lui, sûrement pas, ce n'était pas du tout son } \\
\text { genre. Sa réputation n'a pas ici d'autre } \\
\text { importance que celle d'avoir permis que ces } \\
\text { se soigner, mais en réalité, comme il l'avait }\end{array}$ & $\begin{array}{l}\text { Ich sterbe. ¿Qué es? Son palabras } \\
\text { alemanas. Significan me muero. ¿Pero de } \\
\text { dónde, porqué así de repente? Ya van a ver, } \\
\text { tengan paciencia. Vuelven, vienen de lejos } \\
\text { (como se dice "me viene a la memoria"), de } \\
\text { principio de siglo, de una ciudad termal } \\
\text { alemana. Aunque en realidad vienen de } \\
\text { mucho más lejos aún... Pero no nos } \\
\text { apuremos, antes vayamos a lo más cercano. } \\
\text { Resulta que a principio de siglo -en } 1904 \text {, } \\
\text { para más exactitud- en un cuarto de hotel de } \\
\text { una ciudad termal alemana se incorporó en su } \\
\text { cama un moribundo. Era ruso. Conocen su } \\
\text { nombre: Chejov, Antón Chejov. Era un } \\
\text { escritor de gran reputación, pero eso importa } \\
\text { poco en este caso, pueden estar seguros de } \\
\text { que no pensó en dejarnos una frase célebre de } \\
\text { moribundo. No, él no, seguro que no, no era } \\
\text { para nada su estilo. Su reputación no tiene } \\
\text { aquí otra importancia que el haber permitido } \\
\text { que esas palabras no se perdiesen, como se } \\
\text { habrían perdido si las hubiese pronunciado } \\
\text { algún otro, un moribundo cualquiera. Pero a } \\
\text { ello se limita su importancia. También } \\
\text { importa otra cosa. Como saben, Chejov era } \\
\text { médico. Era tuberculoso y llegó a la ciudad } \\
\text { termal alemana a tratarse, pero en realidad, } \\
\text { como confió a algunos amigos con esa ironía } \\
\text { aplicada, esa feroz modestia, esa }\end{array}$ \\
\hline
\end{tabular}


confié à des amis avec cette ironie appliquée

à lui-même, cette féroce modestie, cette humilité que nous lui connaissons, pour « crever». «Je pars crever là-bas », leur avaitil dit. Donc il était médecin, et au dernier moment, ayant auprès de son lit sa femme d'un côté et de l'autre un médecin allemand, il s'est dressé, il s'est assis, et il a dit, pas en russe, pas dans sa propre langue, mais dans la langue de l'autre, la langue allemande, il a dit à voix haute et en articulant bien «Ich sterbe ». Et il est retombé, mort.

Et voilà que ces mots prononcés sur ce lit, dans cette chambre d'hôtel, il y a déjà trois quarts de siècle, viennent ... poussés quel vent ... se poser ici, une petite braise qui noircit, brûle la page blanche ... Ich sterbe.

Sage. Modeste. raisonnable. toujours si peu exigeant. Se contentant de ce qu'on lui donne... Et il est si démuni, privé de mots... il n'en a pas... ça ne ressemble à rien, ça ne rappelle rien de jamais raconté par personne, de jamais imaginé... c'est ça sûrement dont on dit qu'il n'y a pas de mots pour le dire... il n'y a plus de mots ici... Mais voilà que tout près, à sa portée, prêt à servir... avec cette trousse, ces instruments... voilà un mot de bonne fabrication allemande, un mot dont ce médecin allemand se sert couramment pour constater un décès, pour voy allá a palmar", les dijo. Cuestión que era médico, y en el último momento, con su mujer junto a su cama de un lado y del otro un médico alemán, se incorporó, se sentó y dijo, no en ruso, no en su propia lengua, sino en la lengua del otro, la lengua alemana, dijo en voz alta y articulando bien "Ich sterbe". Y volvió a caer, muerto.

Y esas palabras pronunciadas en esa cama, en ese cuarto de hotel, hace ya tres cuartos de siglo, vienen... arrastradas por qué viento... a posarse aquí, brasita que ennegrece, quema la página blanca... Ich sterbe.

Sensato. Modesto. Razonable. Siempre tan poco exigente. Contento con lo que le dan... Y está tan desprovisto, privado de palabras... le faltan... no se parece a nada, no recuerda nada que nunca nadie haya contado, imaginado... seguro es eso de lo que se dice que no hay palabras para decirlo... ya no hay palabras aquí... Pero resulta que ahí nomás, a su alcance, lista para usarla... con ese estuche, esos instrumentos... una palabra de buena fabricación alemana, una palabra que el médico alemán suele usar para constatar un deceso, para anunciarlo a los parientes, un verbo sólido y fuerte: sterben... gracias, lo tomo, yo también sabré conjugarlo con corrección, sabré servirme de él como se 


\begin{tabular}{|c|c|}
\hline 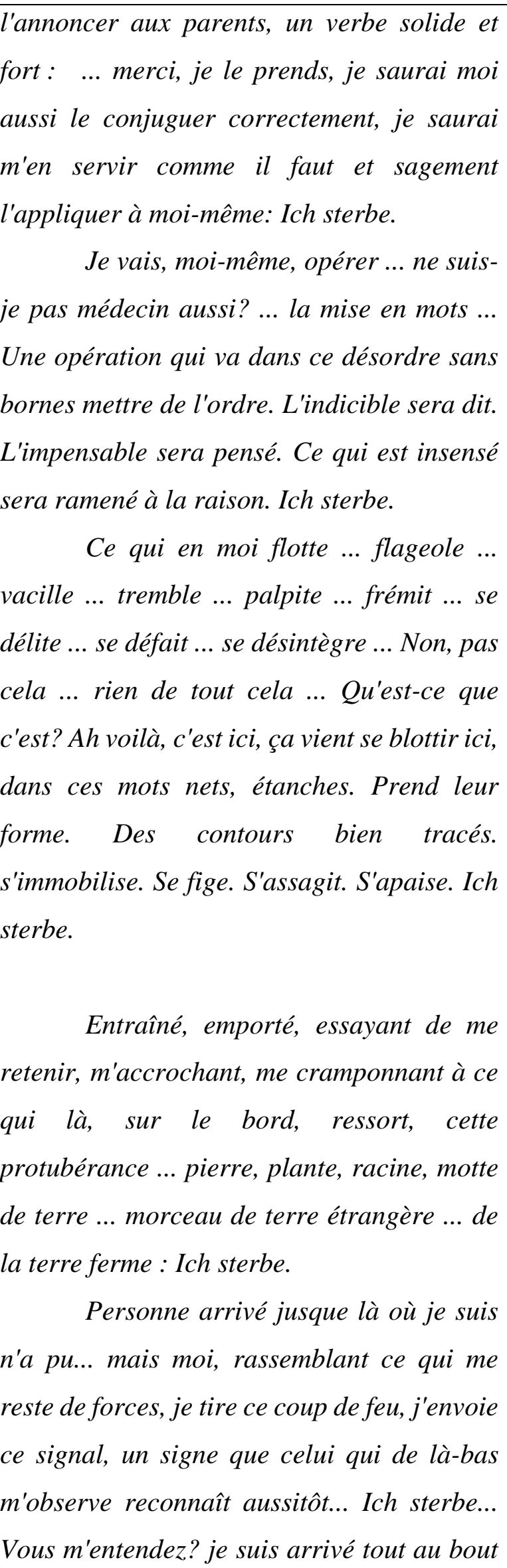 & 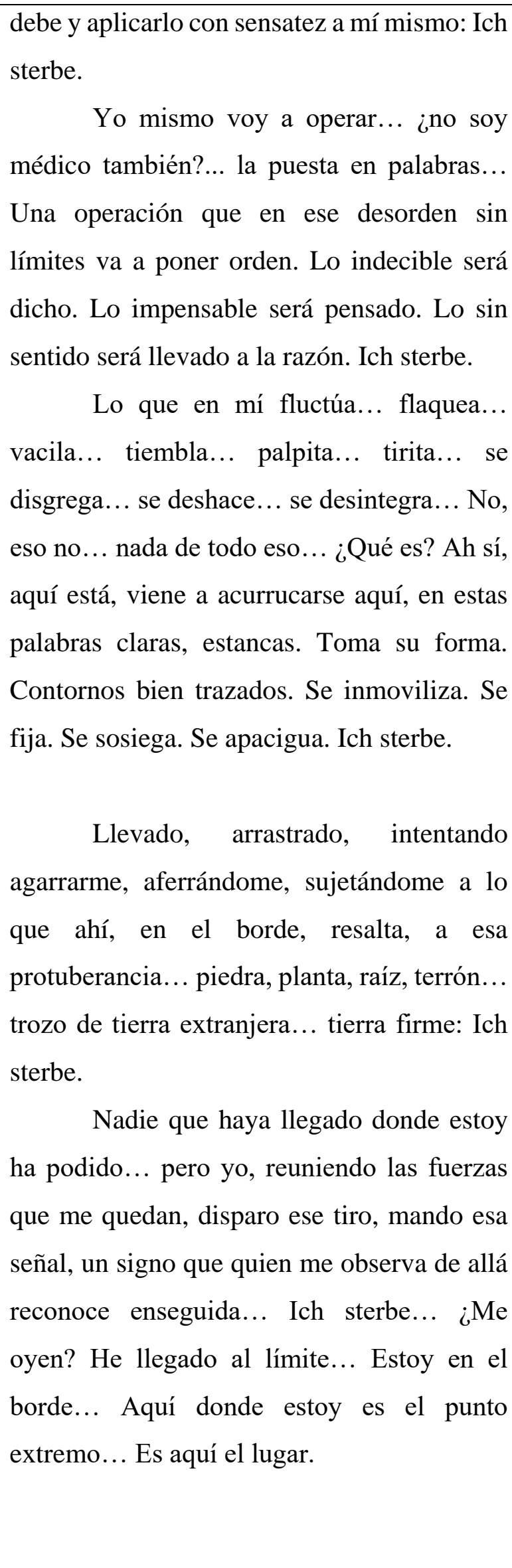 \\
\hline
\end{tabular}


... Je suis tout au bord .. Ici où je suis est le
point extrême... C'est ici qu'est le lieu.
Ich sterbe. Un signal. pas un appel au secours. Là où je me trouve il n'y a pas de secours possible. Plus aucun recours. Vous savez comme moi de quoi il retourne. Personne mieux que vous ne sais de quoi je parle. Voilà pourquoi je parle. Voilà pourquoi c'est à vous que je le dis : Ich sterbe.

A vous. Dans votre langue. Pas à elle qui est là aussi, près de moi, pas dans notre langue à nous. Pas avec nos mots trop doux, des mots assouplis, amollis à force de nous avoir servi, d'avoir été roulés dans les gerbes jaillissantes de nos rires quand nous nous laissions tomber sans forces ... oh arrête, oh je meurs ... des mots légers que le cour battant de trop de vie nous laissions glisser dans nos murmures, s'exhaler dans nos soupirs ... je meurs.

Que dis-tu, mon chéri, mais tu ne sais pas ce que tu dis, il n'y a pas de "je meurs" entre nous, il n'y a que "nous mourons" ... mais ça ne peut pas nous arriver, pas à nous, pas à moi ... tu sais bien comme tu te trompes quand tu vois tout en noir, quand tu as tes moments de désespoir... et tu sais, nous savons, nous avons toujours vu, toi et moi, comme, après, tout s'arrange ... bon, bon, oui, je t'entends ... mais surtout ne te fatigue pas, ne t'excite pas comme ça, ne t'assois pas
Ich sterbe. Una señal. No un pedido de auxilio. Aquí donde me encuentro no hay auxilio posible. Ningún recurso. Saben tanto como yo de qué se trata. Nadie sabe mejor que ustedes de qué hablo. Por eso es a ustedes a quienes digo: Ich sterbe.

A ustedes. En su lengua. No a ella que también está, junto a mí, no en nuestra propia lengua. No nuestras palabras tan dulces, palabras suavizadas, ablandadas de tanto usarlas, de rodarlas en los chorros manantes de nuestra risa cuando nos dejábamos caer sin fuerza... ay basta, ay me muero... palabras leves que latiendo de tanta vida dejábamos deslizar en nuestros murmullos, exhalar en suspiros... me muero.

Qué dices, querido, no sabes lo que dices, no hay "me muero" entre nosotros, sólo hay "nos morimos"... pero eso no puede ocurrirnos, no a nosotros, no a mí... sabes cómo te equivocas cuando ves todo negro, en tus momentos desesperados... y sabes, sabemos, siempre hemos visto, tú y yo, que después se arregla... bueno, sí, sí, te oigo... pero no te canses por favor, no te agites así, no te sientes... no es bueno para ti... ahá, sí, te entiendo, sí, te duele... sí, lo sufres... pero va a pasar, ya verás, como todas las otras crisis... recuéstate por favor, no te muevas, tranquilo...

No, no palabras nuestras, tan leves, tan blandas, nunca podrán franquear lo que ahora entre nosotros se abre, se ensancha... 


\begin{tabular}{|c|c|}
\hline $\begin{array}{l}\text {.. ce n'est pas bon pour toi... là, là, oui, je } \\
\text { comprends, oui, tu as mal ... oui, c'est } \\
\text { pénible... mais ça va passer, tu verras, } \\
\text { comme toutes ces crises les autres fois... mais } \\
\text { surtout recouche-toi, ne bouge pas, sois } \\
\text { calme... } \\
\text { Non, pas nos mots à nous, trop légers, } \\
\text { trop mous, ils ne pourront jamais franchir ce } \\
\text { qui maintenant entre nous s'ouvre, s'élargit... } \\
\text { une béance immense ... mais des mots } \\
\text { compacts et lourds que n'a jamais parcourus } \\
\text { aucune vague de gaieté, de volupté, que n'a } \\
\text { jamais fait battre aucun pouls, vaciller aucun } \\
\text { souffle ... des mots tout lisses et durs comme } \\
\text { des pelotes basques, que je lui lance de toutes } \\
\text { mes forces, à lui, un joueur bien entraîné qui } \\
\text { se tient placé au bon endroit et les reçoit sans } \\
\text { flancher juste là où ils doivent tomber, dans } \\
\text { le fond solidement tressé de sa chistera. } \\
\text { Pas nos mots, mais des mots de } \\
\text { circonstance solennels et glacés, des mots } \\
\text { morts de langue morte. }\end{array}$ & $\begin{array}{l}\text { Desde hace años, meses, días, desde } \\
\text { siempre, ahí estaba, por detrás, mi revés } \\
\text { inseparable... y de un solo golpe, con sólo } \\
\text { dos palabras, en un terrible desgarramiento } \\
\text { me doy vuelta por completo... Pueden verlo: } \\
\text { mi revés se volvió mi derecho. Soy lo que } \\
\text { tenía que ser. Finalmente todo está en orden: } \\
\text { Ich sterbe. } \\
\text { Con estas palabras afiladas, esta hoja } \\
\text { de excelente fabricación, nunca la he usado, } \\
\text { nada la desafiló, me adelanto y yo mismo } \\
\text { corto: Ich sterbe. } \\
\text { Dispuesto a cooperar, tan dócil y de } \\
\text { buena voluntad, antes que ustedes lo hagan, } \\
\text { me ubico donde están, a distancia de mí } \\
\text { mismo, y del mismo modo en que lo harán } \\
\text { emito el dictamen. }\end{array}$ \\
\hline
\end{tabular}


Avec ces mots bien affilés, avec cette
lame d'excellente fabrication, elle ne m'a
jamais servi, rien ne l'a émoussée, je devance
le moment et moi-même je tranche : Ich
sterbe.

Prêt à coopérer, si docile et plein de bonne volonté, avant que vous ne le fassiez, je me place où vous êtes, à l'écart de moimême, et de la même façon que vous le ferez, dans les mêmes termes que les vôtres j'établis le constat.

Je rassemble toutes mes forces, je me soulève, je me dresse, je tire à moi, j'abaisse sur moi la dalle, la lourde pierre tombale ... et pour qu'elle se place bien exactement, sous elle je m'allonge...

Mais peut-être ... quand il soulevait la dalle, quand il la tenait au-dessus de lui à bout de bras et allait l'abaisser sur lui-même ... juste avant que sous elle il ne retombe ... peut-être y a-t-il eu comme une faible palpitation, un à peine perceptible frémissement, une trace infime d'attente vivante ... Ich sterbe ... Et si celui qui l'observait, et qui seul pouvait savoir, allait s'interposer, l'empoigner fortement, le retenir ... Mais non, plus personne, aucune voix... C'est déjà le vide, le silence.
Reúno todas mis fuerzas, me alzo, me incorporo, tiro hacia mí, bajo sobre mí la losa, la pesada lápida... y para que quede bien encajada, bajo ella me acuesto...

Pero tal vez... cuando alzaba la losa, la tenía sobre sí a duras penas e iba a bajarla sobre sí mismo... justo antes de caer bajo ella... tal vez hubo algo como un débil palpitar, un temblor apenas perceptible, rastro ínfimo de espera viva... Ich sterbe... Y si el que lo observaba, único que podía saber, se interponía, lo agarraba fuerte, lo retenía... Pero no, ya nadie, ninguna voz... Ya es el vacío, el silencio.

Éstas son, como ven, sólo unas leves turbulencias, breves ondulaciones entre otras, incontables, que esas palabras producen. $\mathrm{Si}$ a alguno de ustedes el juego le resulta entretenido, puede divertirse -se precisa paciencia y tiempo- encontrando otras. En todo caso, podrá estar seguro de que no se equivoca, lo que encuentre de hecho está ahí, en todos nosotros: círculos que se van ampliando cuando lanzadas de tan lejos y tan fuerte caen en nosotros y nos sacuden de arriba abajo estas palabras: Ich sterbe. 


\begin{tabular}{|l|}
\hline Ce ne sont là, vous le voyez, que \\
quelques légers remous, quelques brèves \\
ondulations captées parmi toutes celles, sans \\
nombre, que ces mots produisent. Si certains \\
d'entre vous trouvent ce jeu distrayant, ils \\
peuvent-il y faut de la patience et du temps \\
- s'amuser à en déceler d'autres. Ils pourront \\
en tout cas être sûrs de ne pas se tromper, \\
tout ce qu'ils apercevront est bien là, en \\
chacun de nous : des cercles qui vont \\
s'élargissant quand lancés de si loin et avec \\
une telle force tombent en nous et nous \\
ébranlent de fond en comble ces mots: Ich \\
sterbe.
\end{tabular}

\section{Breve análise do texto "Ich sterbe"}

O texto "Ich Sterbe" segue as caraterísticas gerais da obra de Sarraute mencionadas acima: questionamento do caráter monolítico do narrador, abertura dialógica ao leitor, ausência de um enredo de aparência exterior, separado da voz do narrador e que seria o seu objeto. No entanto, cabe expor aqui a forma concreta como este texto realiza o projeto sarrautiano.

Authier-Revuz (1984) distingue entre a heterogeneidade constitutiva do discurso e a sua heterogeneidade mostrada. Por um lado, todo discurso é constitutivamente heterogêneo. Ao longo do século XX, diferentes correntes de pensamento, com perspectivas diversas, têm proposto que o sujeito não é fonte exclusiva nem dono do seu dizer, e tentaram expor as fissuras de sua suposta unicidade e homogeneidade. Podemos mencionar, entre outros, Bakhtin (1999) e a sua noção do dialogismo como estrutura interna do discurso. Também, Foucault (2002) e as formações discursivas, onde o sujeito é uma posição nesse campo de interdiscurso. Ou, por exemplo, a psicanálise e a sua proposta de inconsciente estruturado como linguagem, onde, portanto, o sujeito é atravessado, no que ele tem de mais interior, pelo que há de mais exterior. No dizer de Authier-Revuz (1984), o exterior retorna inevitavelmente ao campo da enunciação. A pergunta é: como?

Nesse sentido, Authier-Revuz distingue essa heterogeneidade, constitutiva do sujeito e do seu discurso, da heterogeneidade mostrada. É este último campo - aquilo que se materializa 
na obra e que faz dela, precisamente, uma obra - o que constitui o interesse específico da crítica literária, da crítica de tradução, da prática tradutória. A heterogeneidade mostrada por um discurso diz respeito às "formas linguísticas" que, nele, "representam diversos modos de negociação do sujeito falante com a heterogeneidade constitutiva" (AUTHIER-REVUZ, 1984). Por sua vez, podemos distinguir formas marcadas dessa heterogeneidade mostrada, e formas não marcadas. As primeiras - as formas marcadas - são fragmentos que, no contínuo do discurso, aparecem claramente delimitadas e, assim, mostradas como objeto. Um exemplo de forma marcada é o discurso direto. Outra, a glosa de um fragmento de discurso apresentado de maneira separada, isolada. Temos, neste caso, ruptura sintática em relação ao discurso assumido pelo eu. Outro tipo de marca, que pode se combinar com as anteriores, é a separação por meios gráficos (aspas, itálico) de fragmentos de discurso atribuído a um outro. Localizando heterogeneidade enunciativa, circunscrevendo-a a pontos restritos e claramente delimitados, as formas marcadas podem servir como proteção imaginária da unicidade e autonomia do eu (denegação da heterogeneidade constitutiva).

As formas não marcadas, no entanto, não geram essa ruptura sintática ou gráfica no 102 discurso. Pensemos, por exemplo, no discurso direto livre, ou na presença de fragmentos de outra língua não sinalados graficamente. Nesse caso, os limites entre o próprio e o outro se apagam, perdem nitidez. Assim, como salienta Authier-Revuz, as formas não marcadas de presença da heterogeneidade no próprio discurso são mais "arriscadas" para a unicidade da instância enunciadora. Pois bem: em Sarraute, a proposta narrativa tem a ver, precisamente, com colocar em risco essa instância, com questioná-la. Consequentemente, além de formas marcadas de heterogeneidade, a escrita sarrautiana apresenta tais formas não marcadas de heterogeneidade.

No projeto literário de Sarraute - e o texto "Ich sterbe" não é uma exceção - os movimentos larvários, essa interioridade em processo de devir palavra num movimento de tateio, são inseparáveis da presença da exterioridade e do questionamento do lugar de enunciação do narrador. Esse narrador é interior ao seu discurso e, ao mesmo tempo, já não é dono de si próprio, e se encontra atravessado pelo exterior, pelo outro. É nesse sentido que, coerentemente, em "Ich sterbe" encontramos, além de formas marcadas, diversas formas de heterogeneidade não marcada. Com elas, o que se procura não é circunscrever e neutralizar o estatuto da heterogeneidade, protegendo assim a unicidade do narrador e a objetividade do relato. Pelo contrário, visa-se a radicalizar o questionamento do lugar de fala, que agora é radicalmente interior e radicalmente exterior ao mesmo tempo. 
O que podemos chamar de heterogeneidade de código aparece já desde o título. Uma breve frase em língua alemã, duas palavras, colocam o texto todo sob o signo delas e o pontuam do começo ao fim. Ich sterbe. Forma de heterogeneidade mostrada não marcada: fora as palavras mesmas - reconhecíveis como léxico de uma outra língua -, nenhuma marca aponta esse pertencimento a uma exterioridade (nem de pontuação nem gráficas). As distâncias a respeito dessa instância de alteridade se reduzem, os limites ficam difusos. Ao mesmo tempo, são palavras fundamentais para a estrutura mesma do texto. Nele, estabelece-se uma oposição permanente entre uma língua viva, frágil, vacilante, que procura e se procura, e uma língua técnica, definidora e definitiva, decisória e finalmente morta. Essa dialética atravessa o texto todo e o funda. Assim, é um elemento central da sua forma literária, do sistema que a obra estabelece. Ich sterbe ocupa e encarna o segundo desses polos. Se essas palavras aparecem em uma forma não marcada é, por um lado e como já dissemos, porque toda fala é constitutivamente heterogênea e o projeto de Sarraute é, precisamente, exibir esse fato. Mas também porque, para a autora, falar não é tão simples como escolher entre formas marcadas e não marcadas, ou entre uma língua viva e que busca e uma língua morta e que define, qui tranche. Falar é vacilar, é percorrer a trilha estreita entre um e outro. É o perigo permanente de cair no fundo de um ou de outro deles, na clareza de uma língua morta, ou de uma interioridade viva, encarnada, esperançosa, criadora, mas também escura e por vezes quase incapaz de fala.

Como foi mencionado a respeito do projeto literário da autora em geral, nesse texto também não há um narrador em posição externa ao narrado. Aqui, narrador e narração se confundem: não há um fato narrado exterior, que o narrador possa mirar com onisciência e objetividade. Narrado e narrador são um, na narração. Também se confundem o narrador e o escritor: se não há, estritamente falando, ficção que possa ser contada como enredo exterior, os limites entre voz narrativa e biografia do escritor aparecem, pelo menos, nebulosos.

Como já foi salientado, esse narrador não é monolítico, mas aparece aberto. Aberto à sua própria interioridade, confusa. E aberto a diversas instâncias de exterioridade. Uma dessas instâncias são outras vozes colocadas em cena no fio da narração. Também aqui, a heterogeneidade aparece de forma não marcada: as vozes não emergem separadas do fluxo narrativo, mas em discurso direto livre e, então, na própria voz do narrador que as assume como próprias-outras na primeira pessoa. Também aqui, há "risco" para o narrador monolítico; também aqui, exposição da impossibilidade de separar o interior do exterior.

A primeira dessas outras vozes levadas para o teatro de Sarraute é atribuível a Anton Tchekhov. A presença desse nome é significativo em termos da própria biografia de 
Cherniak/Sarraute. Seria possível arguir, em sentido contrário, que a proposta sarrautiana de questionamento - e, eventualmente, morte do narrador como instância monolítica e dona da sua fala - acarreta como corolário a morte do autor, da instância autoral como significativa para se predicar qualquer coisa a respeito do texto. E, portanto, das circunstâncias biográficas do autor para analisar o texto. Porém, entendo que isso seria enxergar só uma parte da proposta sarrautiana, que visa a colocar essa exterioridade radical no seio de uma interioridade em processo de devir. Assim, a proposta da autora coloca entre parênteses a separação estabelecida pelo construto literário entre instância e voz narrativa e instância autoral e corpo/voz do escritor. Se um e outro (narrador e autor) podem ser colocados em questão, é porque não há limites nítidos entre um e outro, nem entre eles e o que lhes é exterior. E fato literário e fato biográfico têm pertinência com pleno direito. (Ao mesmo tempo, Natalia Cherniak não é Nathalie Sarraute, e uma proposta que coloca em questão os limites entre as vozes, mais do que dispensar a análise delas no construto literário, a convoca.) O texto "Ich sterbe" é publicado em 1980, quando Sarraute tem 80 anos. A autora é de origem russa, e coloca em cena Tchekhov, grande escritor russo. A cena que temos à vista é o momento infinitesimal em que o autor morre, ditando a sua 104 morte: Ich sterbe. A autora, no entanto, encontra-se no final da sua vida e escrevendo sobre a morte, através da morte de outro autor. O russo fala uma língua outra para ditar a sua morte. Podemos pensar que Sarraute, russa de origem, nunca fala - nunca escreve - em uma língua que não seja outra, ao mesmo tempo em que própria. E o texto "Ich sterbe" é uma mise em abîme desse fato.

Há também outra voz em cena, a da esposa de Tchekhov. Assim como no discurso direto livre atribuível a Tchekhov, essa outra voz não é cindida e autossuficiente. A sua forma de emergência é não marcada; ao mesmo tempo, aparece em abertura, em diálogo (neste caso, com a voz do seu marido). Assim, mais do que como personagens clássicos - claramente isoláveis, pretensamente autônomos na sua dependência de um narrador externo e dos "fatos" narrados essas presenças outras aparecem como vozes narrativas diversas desse coletivo de discurso que é a instância narrativa (que o próprio texto é).

Outra forma de abertura e presença do outro no discurso é a interpelação direta ao leitor. Este passa a ser colocado como parte desse diálogo interno ao discurso do texto. Encontramos as marcas dessa inclusão em posições chave do texto: tanto no começo ("Vous allez voir") quanto no final ("si quelq'un d'entre vous"). Por sua vez, as vozes outras que são colocadas em cena replicam essa estrutura: também interpelam, também estabelecem sub-conversações. 
Assim, o movimento interno de busca, de tateio na linguagem, não só acontece entre uma língua escura e viva e uma língua clara e morta. Também entre os meandros dessa busca interior, ancorada em um sujeito que nunca é amo da sua palavra, e no encontro com os outros, que são sempre já parte desse sujeito.

\section{Balizas sobre a tradução para o espanhol de "Ich sterbe"}

A análise acima pretende expor o que, entendo, constitui o miolo, as chaves principais da proposta de Sarraute no texto "Ich sterbe", o sistema dessa obra. A tradução, então, deveria dar conta dessas chaves, recriá-las em um texto outro, mas isomórfico com o original (CAMPOS, 1992). As notas que seguem não pretendem exaustividade. São só algumas balizas que visam a organizar e expor o projeto que guiou a tradução acima apresentada. E que podem, portanto, servir como guia, não exclusivo, para a sua leitura e a sua crítica. Algumas delas poderiam ser consideradas como conservadoras e óbvias, já que se demoram em explicitar a necessidade de "não inovar" em itens que parecem não requerer maior justificativa. Porém, acredito que o melhor caminho na construção de um projeto de tradução (da produção de um texto traduzido e da explicitação dos critérios norteadores) é não considerar nada como óbvio.

\section{* O título e a heterogeneidade de código}

No texto traduzido, o título (Ich sterbe) tem que ser mantido em alemão. A simples presença de uma marca de heterogeneidade de código poderia ser considerada razão suficiente. No entanto, acredito ter aportado, acima, explicações sobre o peso específico dessa presença no sistema da obra. Nesse sentido, é igualmente importante não acrescentar marcas inexistentes no texto original, tais como itálicos (habituais no caso de heterogeneidade de código, ausentes do texto em francês) ou outras. Ich sterbe tem que permanecer como heterogeneidade mostrada não marcada.

\section{* Outras vozes na cena: o discurso direto livre}

Pelo exposto acima, uma vez identificados esses fragmentos de discurso direto livre, interessa conservá-los com esse estatuto. Isto é, garantir o jogo de diferenças com formas marcadas de heterogeneidade, como o discurso direto (que também está presente, como no caso de «Je pars crever là-bas », frase que aparece entre aspas e também é atribuída à voz outra de Tchekhov, que traduzi como "Me voy allá a palmar"). Importa não explicar, nem explicitar, nem sugerir, nem facilitar a compreensão de quem seria o locutor responsável pela fala em 
discurso direto livre: isso tem que resultar da leitura em processo, que, como a escrita, é tateio. Não vou trazer aqui exemplos pontuais, porquanto se trata de um jogo sistemático no texto e que o percorre, praticamente, do começo ao fim. Acredito ter mantido essa forma na tradução.

\section{* A propósito da transliteração do nome "Anton Tchekhov"}

O nome do autor russo é Анто́н Па́влович Че́хов. No texto de Sarraute, como é lógico, achamos o nome escrito segundo o sistema de transliteração para o francês. No meu texto, utilizo a transliteração espanhola "Antón Chejov". Aqui, as diferenças gráficas com o francês (“Tch" / "Ch” e "kh" / “j”) obedecem à conservação aproximada dos fonemas. Quanto à acentuação, o espanhol admite duas transcrições do sobrenome: Chéjov y Chejôv (paroxítona e oxítona, respectivamente). A primeira é a que mais ocorrências registra na Internet e, pelo que entendo, é mais próxima da pronúncia em russo. Neste caso, resolvi usar a segunda, de modo de manter a acentuação do texto francês. Ou seja, de atualizar no meu texto a voz original.

\section{* A interpelação do leitor: uso de formas pronominais e verbais de segunda pessoa.}

Pelo exposto acima, na terceira seção, interessa não apagar as marcas que efetuam essa inclusão do leitor no texto. O seguinte é um caso no começo do texto:

\begin{tabular}{|l|l|}
\hline Ich sterbe. Qu'est-ce que c'est? Ce sont des & Ich sterbe. ¿Qué es? Son palabras alemanas. \\
mots allemands. Ils signifient je meurs. & Significan me muero. ¿Pero de dónde, \\
Mais d'où, mais pourquoi tout à coup? Vous & $\begin{array}{l}\text { porqué así de repente? Ya van a ver, } \\
\text { tengan paciencia. }\end{array}$
\end{tabular}

O espanhol prescinde da explicitação do pronome sujeito; usa-se fundamentalmente como desambiguação e como ênfase. Aqui, a forma de segunda pessoa do plural "van" é igual à da terceira pessoa. Porém, entendo que, no contexto da expressão "ya van a ver" (senão lexicalizada, sim bastante frequente) há desambiguação (aliás, é bastante claro que essa frase não remete ao sujeito "palabras"). A desambiguação é total com o verbo imediato posterior “tengan", que só pode remeter à segunda do plural.

No caso seguinte, já no final do texto,

\begin{tabular}{|l|l|}
\hline Ce ne sont là, vous le voyez, que quelques & Estas son, como ven, sólo unas leves \\
légers remous, quelques brèves ondulations & turbulencias, breves ondulaciones entre \\
\hline
\end{tabular}




\begin{tabular}{|l|l|}
\hline captées parmi toutes celles, sans nombre, & otras, incontables, que esas palabras \\
que ces mots produisent. Si certains d'entre & producen. Si a alguno de ustedes el juego \\
vous trouvent ce jeu distrayant, ils peuvent & le resulta entretenido, puede \\
\hline
\end{tabular}

entendo que "como ven" é suficientemente claro como interpelação (segunda pessoa). Com efeito, aparece como incisa e com uma expressão bastante convencional. E na frase seguinte usa-se explicitamente o pronome pessoal, em “alguno de ustedes". Uma possibilidade para reforçar a interpelação na tradução de vous le voyez seria antepô-la ao sujeito da frase ("Estas”); ou seja, colocar "Como ven," no começo da frase. Porém, pelos motivos já expostos, assim como para manter a cadência da frase francesa, conservamos essa posição.

* Outras interpelações. O esquema de interpelação no nível narrador-leitor é replicado em outros níveis, que habitam a voz desse narrador. Assim, por exemplo, a voz de Tchekhov interpela as pessoas que o ouvem nesse momento final (o médico, a esposa, mas também os leitores):

\begin{tabular}{|l|l|}
\hline $\begin{array}{l}\text { Vous savez comme moi de quoi il retourne. } \\
\text { Personne mieux que vous ne sais de quoi je }\end{array}$ & $\begin{array}{l}\text { Saben tanto como yo de qué se trata. Nadie } \\
\text { sable. }\end{array}$ \\
paror que ustedes de qué hablo. \\
\hline
\end{tabular}

Aqui, o primeiro vous, pronome sujeito, não é reposto em espanhol (atendendo, entre outras coisas, considerações rítmicas). A forma "saben", que a priori é ambígua ( $2^{\mathrm{a}}$ e $3^{\mathrm{a}}$ plural), é desambiguizada no contexto imediato: nele, não há um outro sujeito plural possível; e na frase seguinte, o pronome de segunda pessoa aparece explícito no complemento comparativo.

\section{* Formas impessoais: uso do pronome “On".}

$\mathrm{Na}$ língua francesa, constitui um ponto de presença do outro no próprio. Um forma de encontro do ego e do alter e, nesse entre-deux, a emergência da impossibilidade de atribuição de um sujeito identificável: ça parle.

Aqui um exemplo: 


\begin{tabular}{|l|l|}
\hline $\begin{array}{l}\text { Ils viennent de loin, ils reviennent (comme } \\
\text { on dit : « cela me revient ») }\end{array}$ & $\begin{array}{l}\text { Vuelven, vienen de lejos (como se dice "me } \\
\text { viene a la memoria") }\end{array}$ \\
\hline
\end{tabular}

Entendo que, nesse caso, seria um erro personalizar a forma do pronome traduzido: por exemplo, traduzindo "como decimos" (em tese, a priori, a primeira pessoa do plural é uma das possibilidades de tradução do impessoal $O n$, segundo o contexto). Uma outra possibilidade seria “como uno dice". Neste uso, esse "uno" não está identificado, e nesse sentido permanece como impessoal. Porém, já haveria um princípio de individuação, por quanto é uma instância singular (uno). Também há um princípio de des-neutralização. Nesse sentido, cabe considerar aqui que Sarraute "recusa o entrincheiramento do gênero e reivindica o lugar do neutro na escrita literária" (PEREIRA, 2012). A forma "uno" ecoa o masculino (e de fato, em espanhol, uma enunciadora feminina pode falar "una", com idêntica função). Prefiro, então, o impessoal "se".

Neste outro caso,

\begin{tabular}{|l|l|}
\hline Se contentant de ce qu'on lui donne... & Contento con lo que le dan... \\
\hline
\end{tabular}

resolvi o uso da forma plural com valor de impessoal. Por um lado, porque em espanhol é a forma de impessoal habitual nessa colocação. Também por razões vinculadas com o elemento do ritmo (que vou comentar mais à frente): acrescentar o "se" ("contento con lo que se le da") alongaria a frase e geraria uma repetição vocálica do som E (três vezes), fazendo-a menos fluida.

* O discurso como tateio: desdobramentos. Semântica e significância.

Uma caraterística central da forma literária do texto de Sarraute percorre os diversos pontos abordados na terceira seção deste artigo. Trata-se do discurso como tateio. É o correlato do narrador como não-mestre do seu discurso. A fala - a escrita - é busca. Procura dizer o indizível; enunciar essa interioridade que não é tal; articular em palavras a experiência da consciência, que é - sempre-já - atravessada pelo outro; dar voz ao que é vivo, sob o risco de matá-lo com palavras. Desse tateio do discurso, se desprendem pelo menos três considerações.

A primeira delas tem a ver com o léxico e sua riqueza. A busca implica, entre outras coisas, jogos de variações diferenciais. Na tradução, interessa manter esses jogos de variações, não aplanar o repertório. Não vou trazer aqui muitos exemplos - que, aliás, custaria escolher. 
Trago um caso só, diretamente vinculado com o tema explícito e com o título do texto. Tratase de crever.

\begin{tabular}{|l|l|}
\hline Il était tuberculeux et il était venu là, dans & Era tuberculoso y llegó a la ciudad termal \\
cette ville d'eaux, pour se soigner, mais en & alemana a tratarse, pero en realidad, como \\
réalité, comme il l'avait confié à des amis & confió a algunos amigos con esa ironía \\
avec cette ironie appliquée à lui-même, & aplicada a sí mismo, esa feroz modestia, esa \\
cette féroce modestie, cette humilité que & humildad que le conocemos, a "palmar”. \\
nous lui connaissons, pour « crever ». «Je & "Me voy allá a palmar”, les dijo. \\
pars crever là-bas », leur avait-il dit. &
\end{tabular}

Em um nível muito alto de abstração, crever poderia ser considerado "sinônimo" de mourir, morrer. Mas se, já de maneira geral, podemos interrogar a consistência da noção de sinônimo, a obra de Sarraute exige ainda mais essa interrogação. A forma de tateio do texto Sarrautiano requer atenção aos jogos de matizes (entre palavras de um mesmo campo semântico, entre palavras "sinônimas", etc.). Aqui, a questão atravessa o elemento dos registros de discurso, neste caso o registro familiar. Acredito que é importante manter esse jogo de registros e - sem chegar ao uso de expressões de outros registros, como o vulgar - evitar aplanar o repertorio léxico (por exemplo, aqui, sobre o termo neutro morir). O Dicionário da Real Academia Española dá, para a entrada palmar: "1. intr. coloq. Dicho de una persona: morir (\| llegar al término de la vida)"; o dicionário Maria Moliner define: "intr. inf. *Morir. También, palmarla". Em ambos os casos, trata-se de um termo indicado como coloquial (DRAE) ou informal (MM), mas não vulgar. Também não é marcado regionalmente, nem como parte de um socioleto particular. Nesse sentido, e no contexto da frase - em que se diz que Tchekhov fala com ironia aplicada a si próprio e com humildade -, entendo que é adequada a tradução "palmar". Sublinhemos, porém, que não se trata aqui só de semântica no sentido do significado do signo. Trata-se de atualizar na tradução outras dimensões da significância (MESCHONNIC, 2012) do termo e do texto (tais como os jogos de registros de fala, os jogos de matizes, repetições e alterações nesse texto que tateia, etc).

\section{* A dimensão gráfica}

Uma segunda consideração vinculada com o mencionado tateio do discurso tem a ver com um aspecto que, às vezes, é desconsiderado no texto literário: a importância da sua 
dimensão gráfica. Longe de ser um mero meio físico acidental - resultante da necessidade de dar um "corpo" ao texto - ou simples enfeite, é um elemento constitutivo da fisicalidade do texto como dimensão do sistema da obra. Vou referir aqui dois elementos vinculados a tal dimensão. O primeiro deles é a pontuação. Em particular, aqui, as reticências são fundamentais. Com efeito, Sarraute "costuma [...] salpicar o texto de sinais de reticências, que significam uma pausa na fala, ou interrupções [...] o não dito, o silêncio" ( PEREIRA, 2012). Em "Ich sterbe", elas percorrem as diversas ocorrências de discurso direto livre, conferindo, precisamente, a textura de uma fala que se busca. Na tradução, mantê-las em todas as suas ocorrências é importante, assim como manter a minúscula nas proposições logo depois das reticências.

Um outro elemento da dimensão gráfica é a disposição dos parágrafos: os limites entre eles, mas, também, a distância na página. O arranjo dos parágrafos é, em geral, um "aspecto caro a Sarraute" (PEREIRA, 2012). Em "Ich sterbe" em particular, há blocos de parágrafos continuados, sem linhas vazias entre eles. Também há parágrafos separados por uma linha vazia ou, finalmente, outros com separação de duas linhas entre eles. Se a escrita é uma voz que se procura em um movimento de tateio, o texto é o corpo dessa voz, e a disposição dos parágrafos

110 faz parte do ritmo dela. Considerar este elemento como essencial ao texto foi o que me levou a apresentar os textos francês e espanhol na sua defasagem própria, devida à diferença de comprimento dos textos (em vez de alinhar parágrafo com parágrafo, para um contraste mais fácil dos textos original e traduzido).

\section{* Sobre o ritmo}

A respeito dessa defasagem, trago a última das considerações deste comentário da tradução. Ela tem a ver com a dimensão do ritmo. Como adverte Meschonnic, considerar o ritmo na tradução não se limita "a lembrar, banalmente, [...] que um texto tem ritmo, e que a tradução deve leva-lo em conta"3 (MESCHONNIC, 2012, p. 122, tradução minha). Também não pretendo propor aqui uma "tradução meschonniqueana". Trata-se de considerar o ritmo como movimento da palavra no texto, de entendê-lo como corpo do texto em processo. Com efeito, para o autor, o ritmo de um texto dá conta de sua fisicalidade, é o corpo do texto como voz. Segundo Meschonnic, a oralidade de um texto, a sua voz, remete a uma corporeidade que, por sua vez, remete a uma socialidade.

Como acostuma acontecer na experiência tradutória, neste caso uma primeira tradução resultou um pouco mais próxima da linearidade do texto, e esteve mais preocupada com seu aspecto semântico básico. Nas revisões, achei importante focar um elemento fundamental da 
prosa de Sarraute, que já foi indicado: interessava colocar em destaque o entendimento do texto como movimento larvário, às portas da consciência, que se faz voz num processo de busca e de abertura à alteridade. Interessava, então, captar esse movimento. Nesse sentido, foi natural remeter a Meschonnic e suas considerações a respeito do ritmo como movimento da palavra. Assim, a dimensão rítmica foi incorporada como fator relevante na etapa de revisão.

Sem tentar uma análise pormenorizada das dimensões rítmicas do texto de Sarraute, na revisão considerei, como critérios orientadores válidos, as dimensões da métrica e da cadência sintática (aproximadas). Isso levou a encurtar algumas frases, fazê-las mais enxutas, para aproximá-las da métrica e da cadência do original, sempre na medida do possível. Foi um dos elementos que fez com que o texto espanhol fosse graficamente mais curto que o francês. Com efeito, a língua francesa falada tem uma distância importante em relação à escrita. Muitas letras não têm um correlato como fonemas, mas são informação morfológica "muda" no oral (desinências verbais, etc.), ou fazem parte de conjuntos de letras que têm como correlato um fonema só. Assim, o francês falado é mais "breve" do que o escrito. Essa defasagem é muito maior do que no caso da língua espanhola. A minha tradução tenta seguir mais de perto a oralidade do texto francês, e não a sua expressão gráfica; dali a diferença gráfica observada no comprimento dos textos, na tabela acima.

Outro elemento rítmico diz respeito dos jogos de repetições, variações e matizes, que pontuam o texto. Algo já foi dito acima em relação com esse ponto, quando foi abordada a tradução da palavra crever. Aqui cabe sublinhar que acolher a dimensão rítmica implica não pensar no significado de palavras isoladas como unidade de tradução, mas na significância do texto, ditada entre outras coisas por tais jogos como parte da sua dimensão rítmica.

\section{Considerações finais}

Este artigo visou, primeiramente, a apresentar a tradução de um texto de Nathalie Sarraute inédito em espanhol. Em segundo lugar, esboçar um comentário da tradução. Mais do que fazer um inventário detalhado das decisões tradutórias e das suas justificativas, as considerações acima visam, a trazer algumas reflexões sobre a experiência de traduzir o texto "Ich sterbe". Também, aportar alguns elementos que possam servir de parâmetros para uma eventual crítica da tradução apresentada. Porém, esses objetivos de trabalho, enumerados aqui de maneira preliminar, não esgotam a questão.

No limite, a crítica (de terceiros) pode prescindir do conhecimento da língua do original, focando os comentários quer na descrição do texto traduzido, quer na relação entre os textos 
original e / ou traduzido - acontecida ou esperada - com os respectivos sistemas literários (do texto original, do texto traduzido). Porém, esse não é o caso da tradução comentada pelo próprio tradutor. Esta precisa, por um lado, desvendar as questões de tradução fundamentais que o texto lhe apresenta. Para isso, é importante considerar o texto em contexto, na sua abertura, em diálogo com a obra do autor (mais ainda, com a literatura do seu tempo, em particular do seu próprio sistema literário, areia discursiva onde a obra considerada irrompe). Por outo lado, apresentar uma proposta de trabalho, que leve em conta essas questões chave e as pense na língua de chegada, como discurso, para fazer o que o texto original faz na sua língua (MESCHONNIC, 2012). Finalmente, comentar a tradução. Isto é, referir elementos do texto traduzido - pontuais ou globais- às decisões fundamentais de tradução e que conformam o projeto de tradução (BERMAN, 1995), dando-lhe uma sustância concerta.

O trabalho nesses três níveis poderia ser matéria para uma tese ou uma dissertação. Neste artigo, mais modestamente, tentei analisar e expor alguns traços fundamentais em cada um desses três níveis. Assim, nas duas primeiras seções foram explicitadas algumas caraterísticas gerais da obra de Sarraute, em diálogo com seu contexto literário. Em relação com

112 os elementos ali apresentados, a quarta seção procurou expor uma análise (ou, melhor, um esboço ou começo de análise) do texto em questão, “Ich sterbe”. Para isso, entendo que as noções de formas marcadas e não marcadas da heterogeneidade mostrada (AUTHIER-REVUZ, 1984) estabelecem um diálogo frutífero com a obra de Sarraute e com o texto considerado. Em particular, com o questionamento do estatuto do narrador como entidade monolítica; e com a escrita como tateio, exploração da emergência de uma língua viva numa interioridade que, ao mesmo tempo, se apresenta sob a forma de exterioridade e de encontro, de diálogo. Outra noção que, entendo, dialoga com a obra de ritmo (MESCHONNIC, 2012) apresentada na quinta e última seção. Nela, avanço sobre questões de tradução mais específicas, expondo minhas propostas de trabalho em cada um desses vectores e dando-lhes um conteúdo concreto com elementos extraídos do texto traduzido.

A exposição de um projeto de tradução (ou de um esboço de projeto) importa, no primeiro lugar, para a explicitação do fato seguinte: não há um único projeto possível. As diferenças entre projetos podem resultar de diferenças na análise das questões de tradução chave, que o texto apresenta ao tradutor. Mas, também, por diferenças no trabalho na língua de tradução, que o tradutor assume - conscientemente ou não - para dar resposta a tais questões. Para trazer só um exemplo, outro projeto possível poderia propor, de maneira totalmente válida, a tradução para uma variante da língua espanhola. No segundo lugar, expor um projeto implica 
um trabalho de autocrítica, ou, mais modestamente, de tentativa de explicitação dos próprios pressupostos. No terceiro lugar, constitui um guia para a prática da tradução (que, porém, não a precede, mas cristaliza em diálogo com essa prática). No quarto lugar, fornece uma ferramenta para o retorno crítico ao texto traduzido: do próprio tradutor sobre seu texto e sobre seus pressupostos; ou de um terceiro, um crítico. Finalmente -e esta é, talvez, a aposta ou o propósito deste artigo, para além dele- pode ser um germe para desenvolver um projeto de tradução mais vasto da obra de Sarraute. Por exemplo, do livro L'usage de la parole, que "Ich sterbe" integra e que ainda está inédito em espanhol.

\section{REFERÊNCIAS BIBLIOGRÁFICAS}

AGENCIA ARGENTINA DE ISBN. Disponível em: <http://www.isbn.org.ar/>. Acesso em: 30 nov. 2017.

AUTHIER-REVUZ, Jacqueline. Hétérogénéité(s) énonciative(s). In: Langages v. 19, n. 73, p. 98-111 , 1984. Disponível em: <http://www.persee.fr/doc/lgge_0458-

726x_1984_num_19_73_1167>.Acesso em: 1 dez. 2017.

BAJTIN, Mijail. Estética de la creación verbal. Tradução Tatiana Bubnova. 10. ed. México, México: Siglo XXI, 1999.

BASE DE DATOS DE LIBROS EDITADOS EN ESPAÑA. Disponível em: $<$ https://www.mecd.gob.es/cultura-mecd/areas-cultura/libro/bases-de-datos-del-isbn/base-dedatos-de-libros.htm>. Acesso em: 30 nov. 2017.

BERMAN, Antoine. Pour une critique des traductions: John Donne. Paris, França: Gallimard (Bibliothèque des idées), 1995.

CAMPOS, Haroldo De. Da tradução como criação e como crítica. In: Metalinguagem e outras metas. 2a edição. São Paulo: Perspectiva, 1992. p. 31-48.

FOUCAULT, Michel. La arqueología del saber. Buenos Aires, Argentina: Siglo XXI, 2002.

PEREIRA, Germana Henriques. Nathalie Sarraute: a "era da suspeita", a delimitação de um novo cânone, e sua tradução. In: Traduzires v. 1, n. 2 , 2012. Disponível em:

<http://periodicos.unb.br/index.php/traduzires>. Acesso em: 30 nov. 2017.

LA CENTRAL. Disponível em: <https://www.lacentral.com/sarraute-nathalie/adrianahidalgo/retrato-de-un-desconocido/9789879396735> . Acesso em: 26 maio 2018.

MESCHONNIC, Henri. Poétique du traduire. Verdier (Poche), 2012.

SARRAUTE, Nathalie. Ich sterbe. L'usage de la parole. Paris: Gallimard, 1980. 


\begin{abstract}
${ }^{1}$ Nicolás GÓMEZ - Mestrando em Estudos da Tradução na Universidade de Brasília. Graduado em Sociologia (2008) pela Universidad de Buenos Aires, Argentina. Lattes: http://lattes.cnpq.br/2682426454036518 ORCID: https://orcid.org/0000-0002-9542-795X E-mail: marsharu@gmail.com

${ }^{2}$ L'ouvre finale est achevée, définitive, mais elle garde toujours quelque chose de cette phase de gestation, de tâtonnement, à partir de laquelle elle a bifurqué vers sa figure finale.

${ }^{3}$ Dans l'état actuel de la théorie du langage et de la littérature, confronter les deux termes de rythme et de traduction ne consiste plus à rappeler, banalement, stylistiquement, qu'il y a du rythme dans un texte, et que la traduction doit en tenir compte.
\end{abstract}

